University of Wollongong

Research Online

Faculty of Engineering and Information

Faculty of Engineering and Information

Sciences - Papers: Part B

Sciences

2019

Performance Simulation and Evaluation of Net Zero Energy Buildings in an Australian Coastal Climate

Joel Anderson

University of Wollongong, jla987@uowmail.edu.au

Duane A. Robinson

University of Wollongong, duane@uow.edu.au

Zhenjun $\mathrm{Ma}$

University of Wollongong, zhenjun@uow.edu.au

Follow this and additional works at: https://ro.uow.edu.au/eispapers1

Part of the Engineering Commons, and the Science and Technology Studies Commons

Research Online is the open access institutional repository for the University of Wollongong. For further information contact the UOW Library: research-pubs@uow.edu.au 


\title{
Performance Simulation and Evaluation of Net Zero Energy Buildings in an Australian Coastal Climate
}

\begin{abstract}
Net zero energy buildings (NZEB) are becoming more common, and as new energy saving designs and technologies become available, the ability to estimate overall energy use and understand the impact on operation of building appliances will become important. This paper outlines simulation results of performance improvements achieved by modifying various components (glazing, lighting, thermal comfort settings) of two tertiary education NZEBs and a typical modern commercial building. The DesignBuilder models' thermal performance and energy consumption were validated using real data from case study buildings. The work shows validating models of smaller, less conven-tional, buildings is more difficult than for larger conventional ones. Performance of NZEBs was benchmarked against the typical commercial building, and subsequently the impact of alterations to overall energy savings established. Results illustrate that NZEBs appear more sensitive to design changes. The work indicates significant savings are achievable in NZEBs and conventional buildings if suitable glazing is selected, lighting controlled according to daylight, or comfort band settings adjusted appropriately. Poten-tial savings are quantified using models developed and validated in simulation.
\end{abstract}

\section{Keywords}

climate, coastal, simulation, performance, evaluation, net, zero, energy, buildings, australian

\section{Disciplines}

Engineering | Science and Technology Studies

\section{Publication Details}

Anderson, J., Robinson, D. A. \& Ma, Z. (2019). Performance Simulation and Evaluation of Net Zero Energy Buildings in an Australian Coastal Climate. In R. J. Howlett \& L. C. Jain (Eds.), International Conference on Sustainability in Energy and Buildings Switzerland: Springer Nature. 


\title{
Performance Simulation and Evaluation of Net Zero Energy Buildings in an Australian Coastal Climate
}

\author{
Joel Anderson ${ }^{1}$, Duane A. Robinson ${ }^{1}$, Zhenjun $\mathrm{Ma}^{1}$ \\ ${ }^{1}$ Sustainable Buildings Research Centre, University of Wollongong, NSW 2522, Australia \\ duane@uow.edu.au
}

\begin{abstract}
Net zero energy buildings (NZEB) are becoming more common, and as new energy saving designs and technologies become available, the ability to estimate overall energy use and understand the impact on operation of building appliances will become important. This paper outlines simulation results of performance improvements achieved by modifying various components (glazing, lighting, thermal comfort settings) of two tertiary education NZEBs and a typical modern commercial building. The DesignBuilder models' thermal performance and energy consumption were validated using real data from case study buildings. The work shows validating models of smaller, less conventional, buildings is more difficult than for larger conventional ones. Performance of NZEBs was benchmarked against the typical commercial building, and subsequently the impact of alterations to overall energy savings established. Results illustrate that NZEBs appear more sensitive to design changes. The work indicates significant savings are achievable in NZEBs and conventional buildings if suitable glazing is selected, lighting controlled according to daylight, or comfort band settings adjusted appropriately. Potential savings are quantified using models developed and validated in simulation.
\end{abstract}

Keywords: Building simulation, Building energy, Net zero energy, Energy efficiency.

\section{Introduction}

This paper presents the performance simulation of three case study buildings including two recently completed net zero energy buildings (NZEB). The originality of this work is to examine potential of improvements of NZEBs and conventional buildings by altering various components and provide useful information which can be used to facilitate effective design for enhanced performance. Section 2 provides a brief literature review on NZEBs. Section 3 details the case study buildings, and compares energy use of NZEBs to more typical commercial buildings. The simulation approach and validation are presented in Sections 4 and 5. Results are compared to real weather and energy data collected. Alterations to glazing, lighting control and thermal comfort settings are analyzed for impact on energy use. Results from this analysis of varying degrees of technology and control are presented in Section 6 . Sections 7 and 8 provide discussion on the impact on performance and concludes.

\section{Net Zero Energy Buildings}

With NZEBs a promising solution to emissions reduction in the built environment, cost effective and higher performing design is essential for success. A greater understanding of design and operation of efficient buildings is required, especially interaction of building elements and their net impact on energy use. In [1] heating, ventilation, and air conditioning (HVAC) energy savings of $40 \%$ were identified through application of passive design, i.e. thermal insulation, glazing and shading. Factors having most influence on energy use are orientation, shape and compactness (ratio of external surface area to internal volume) [2]. Thus, NZEBs will be most effective when designed from new. Retrofitting to create a NZEB provides challenges, and buildings with greatest potential for energy efficiency improvements, and adequate roof space for photovoltaic (PV) systems, are most likely to achieve NZEB status. Reducing demand needs to be a prerequisite to sizing of renewables [3, 4]. With a properly designed passive envelope HVAC requirements can be minimized [5], and 
in some moderate climates be unnecessary [6]. In developed countries HVAC accounts for approximately $50 \%$ of built environment energy use and $20 \%$ of national energy use [7]. Installed HVAC capacity has risen with increasing desire for thermal comfort [7]. Even with passive design, significant HVAC efficiency measures will need development.

Approximately $30 \%$ of building energy can be attributed to lighting [8]. An important consideration of lighting is its impact on thermal load (waste heat creating follow-on effects for HVAC). One way to reduce these effects is to introduce more daylighting. Optimizing daylighting can reduce lighting energy by $50 \%-80 \%$ [8]. Increasing daylighting aperture (product of window visible transmittance and window-perimeter floor area ratio) can lead to a significant increase in energy savings [9]. Diminishing returns occur at an aperture of 0.3 , a result consistent across varying geographical locations. A window-to-wall area ratio of no more than $30 \%-40 \%$ also improves energy use [10].

\section{Case Study Buildings}

Three case study buildings were considered, two recently completed NZEBs, and a modern commercial building of more conventional design. The buildings are located within $20 \mathrm{~km}$ of each other in a coastal region of New South Wales, Australia. The first NZEB is the Sustainable Buildings Research Centre (SBRC), located at University of Wollongong. SBRC is a 2,600 $\mathrm{m}^{2}$ double story research facility with two wings, designed to be a sustainability flagship. An east-west building axis and separation between two main wings ensures maximum passive ventilation and natural light. The first wing is $1,700 \mathrm{~m}^{2}$ of academic offices, training spaces, flexible working spaces, laboratories and exhibition area. Second wing is a $900 \mathrm{~m}^{2}$ high bay and rooftop laboratory. $159 \mathrm{~kW}_{\mathrm{p}}$ of PV is installed. The second NZEB is the Transformational Technical Training (TTT) facility, located at TAFE Illawarra. TTT is used for educational and demonstration purposes. $28 \mathrm{~kW}_{\mathrm{p}}$ of PV is installed. The third case study building is Enterprise 1, is a more conventional commercial building, located on same site as SBRC. Enterprise 1 houses a variety of commercial and university tenants, achieved 5 Star base-build National Australian Building Energy Rating System rating [11], and considered state-of-the-art for its sector. Physical geometry of each case study building is illustrated in Fig. 1 to 3, and a summary of basic details provided in Table 1.

Table 1. Summary of the Basic Details for each Building.

\begin{tabular}{|c|c|c|c|c|}
\hline Building detail & SBRC Building & \multicolumn{2}{|c|}{ TTT Building } & \\
\hline Building use & Education and research & \multicolumn{2}{|c|}{ Education and training } & Commercial \\
\hline Floor area & $2,600 \mathrm{~m}^{2}$ & \multicolumn{2}{|c|}{$1,020 \mathrm{~m}^{2}$} & $10,000 \mathrm{~m}^{2}$ \\
\hline Lighting power density & $\mathrm{y} 1.6 \mathrm{~W} / \mathrm{m}^{2}$ & \multicolumn{2}{|c|}{$4.75 \mathrm{~W} / \mathrm{m}^{2}$} & $9.4 \mathrm{~W} / \mathrm{m}^{2}$ \\
\hline Glazing type & Double glazed & \multicolumn{2}{|c|}{ Double/Single } & glazed \\
\hline VAC comfort band & $20^{\circ} \mathrm{C}-24^{\circ} \mathrm{C}$ & \multicolumn{2}{|c|}{$20^{\circ} \mathrm{C}-24^{\circ} \mathrm{C}$} & $21^{\circ} \mathrm{C}$ \\
\hline VAC & $\begin{array}{l}2 \times 17 \mathrm{~kW} \text { GSHP, } 110 \mathrm{~kW} \text { ASHP, } \\
3 \times 91 \mathrm{~m} \text { vertical bore and } \\
\text { 12x125 m loop horizontal GHX }\end{array}$ & \multicolumn{2}{|c|}{$\begin{array}{l}4 \times 15 \mathrm{~kW} \text { WWHP, } 6 \mathrm{~kW} \\
\text { ASHP, 8x90 m vertical } \\
\text { borehole GHX }\end{array}$} & $\begin{array}{l}\text { 2x600 kW chillers, } \\
\text { 2x202 kW gas boil- } \\
\text { ers, } 13 x \text { AHU’s }\end{array}$ \\
\hline Renewable energy & $155 \mathrm{~kW}_{\mathrm{p}}$ solar PV, $4 \mathrm{~kW}_{\mathrm{p}}$ BIPVT & $28 \mathrm{kV}$ & Ip solar PV & None \\
\hline & \multicolumn{4}{|c|}{ Table 2. Building Performance Simulation Methodology. } \\
\hline nent & \multicolumn{2}{|l|}{ Aim of experimentation } & \multicolumn{2}{|c|}{ Performance parameters measured } \\
\hline Glazing & \multicolumn{2}{|c|}{$\begin{array}{l}\text { Assess comparative energy performance } \\
\text { of various glazing technologies }\end{array}$} & \multicolumn{2}{|c|}{$\begin{array}{l}\text { Lighting, HVAC, and overall building } \\
\text { energy use }\end{array}$} \\
\hline Lighting control & \multicolumn{2}{|c|}{$\begin{array}{l}\text { Assess the effects of daylight sensors in } \\
\text { controlling artificial light output }\end{array}$} & \multicolumn{2}{|c|}{$\begin{array}{l}\text { Lighting and overall building energy } \\
\text { use }\end{array}$} \\
\hline Window shading & \multicolumn{2}{|c|}{$\begin{array}{l}\text { Determine potential energy impacts of } \\
\text { window shading }\end{array}$} & \multicolumn{2}{|c|}{$\begin{array}{l}\text { Lighting, HVAC, and overall building } \\
\text { energy use }\end{array}$} \\
\hline HVAC & \multicolumn{2}{|c|}{$\begin{array}{l}\text { Assess the energy effects of incremental } \\
1^{\circ} \mathrm{C} \text { changes in comfort set-point }\end{array}$} & \multicolumn{2}{|c|}{ HVAC, and overall building energy use } \\
\hline
\end{tabular}




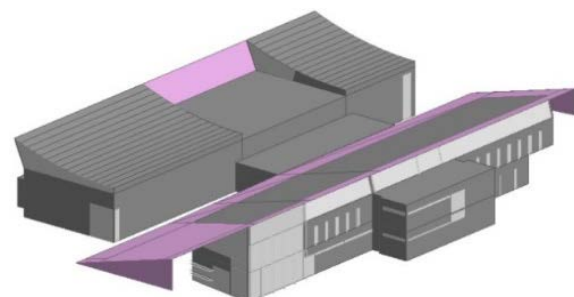

Fig. 1. SBRC building physical geometry.

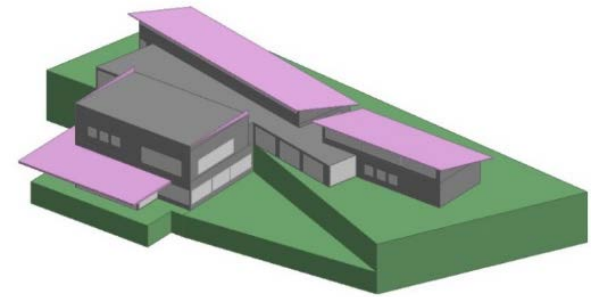

Fig. 2. TTT building physical geometry.

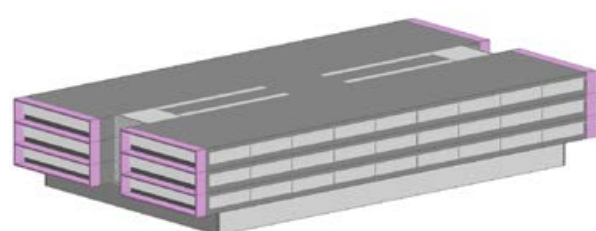

Fig. 3. Enterprise 1 building physical geometry.

Table 3. Thermal Model Validation Results.

\begin{tabular}{llcc}
\hline Zone & $\begin{array}{c}\text { Avg. } \\
\text { NMBE (\%) }\end{array}$ & $\begin{array}{c}\text { Avg. } \mathbf{R}^{\mathbf{2}} \\
\mathbf{( \% )}\end{array}$ \\
\hline TTT & Ground floor office & -1.1 & 85.6 \\
& Seminar room & -0.5 & 78.0 \\
& Simulation room & -7.6 & 82.6 \\
& Gallery & -10.1 & 86.4 \\
\hline SBRC & Energy lab & 7.5 & 16.4 \\
& Water lab office & 3.1 & 60.0 \\
& Eastern office & 5.8 & 17.0 \\
\hline
\end{tabular}

\section{Building Simulation Methodology}

All case study buildings were modelled using DesignBuilder software [12]. Information sourced from schematics, operations manuals, and metered temperature and energy data were used to characterize physical, operational and thermal qualities. Four scenario categories were chosen for investigation, covering major building elements: glazing, lighting, window shading and HVAC (refer to Table 2). Simulation scenarios were inputs to the validated model in DesignBuilder, along with Typical Meteorological Year (TMY) weather files. The change in net energy as a result of adopted scenarios was determined. Scenario performance indicators show how each different technology was measured. Prior to scenario simulations, it was established that each model was a valid representation of the case study building.

\section{$5 \quad$ Validation of Building Models}

A two-tiered approach was taken for validation. The first was a thermal comparison between average zone temperatures simulated by the model and those measured in reality, the second, a comparison between energy consumption of building systems from the model with those measured by meters in reality. In the validation stage, historical TMY (averaged) weather data could not be used as it differs significantly from real data. Meteorological data recorded close to the sites was used for periods where measured and modelled data were able to be matched. For validation of the energy tier of the model, the method as specified by the American Society of Heating, Refrigeration, and Air Conditioning Engineers (ASHRAE) Guideline 14-2002 [13] was used. Specifically, normalized mean bias error (NMBE) and coefficient of variation of root mean square error (CVRMSE) given by (1) and (2). CVRMSE is a measure of how well modelling fits the data, while NMBE is used to account for any presence of offset errors not accounted for by CVRMSE. A maximum CVRMSE of $15 \%$ and NMBE of $10 \%$ was chosen from [13].

$N M B E=\frac{\sum\left(y_{\text {measured }}-y_{\text {modelled }}\right)}{\sum y_{\text {measured }}} \times 100$

$$
\text { CVRMSE }=\frac{\sqrt{\overline{\left(y_{\text {measured }}-y_{\text {modelled }}\right)^{2}}}}{\bar{y}_{\text {measured }}} \times 100
$$

where $y_{\text {measured }}$ is the measured data point and $y_{\text {modelled }}$ is the corresponding modelled data. Validation of the thermal tier of the model used NMBE, along with the coefficient of determination, $\mathrm{R}^{2}$, to indicate the degree of correlation between modelled and measured data. 


\subsection{Thermal Validation}

As an example of the process of model validation for thermal attributes of TTT, the ground floor office modelled temperature versus actual is shown in Fig. 4. Overall, temperature profiles from the model compared well with those measured. NMBE for the relevant data was $1.1 \%$, indicating the model over predicted temperatures slightly for this zone. $\mathrm{R}^{2}$ was $86 \%$ indicating a good fit between modelled and real data. Similar figures were obtained for other zones within TTT. The slight overestimation of temperatures in the TTT model may be attributed to usual modelling errors, i.e. simplified physical model, occupancy level assumptions, insulation performance, equipment use, etc., and that solar radiation data at TTT was close enough to that of SBRC (although being $20 \mathrm{~km}$ away). Use of solar data measured at SBRC weather station was necessary owing to TTT weather station being inaccessible. A smaller solar heat gain into TTT would explain some of the difference in temperature. As this is an educational building, occupancy rates fluctuate throughout the year and are difficult to predict and survey. Follow-on effects from occupancy which are difficult to account for, such as HVAC set-point adjustment, may also contribute to differences.

Thermal validations of SBRC zones were generally less successful than TTT. An example is shown in Fig. 5 for SBRC Water Laboratory. NMBE and $\mathrm{R}^{2}$ for this zone were $4.1 \%$ and $55.8 \%$. Reasonably good behavior of the model with reference to real data was obtained. A summary of thermal validation results for SBRC and TTT models is shown in Table 3. Thermal validation of Enterprise 1 was not possible due to no access to temperature data.

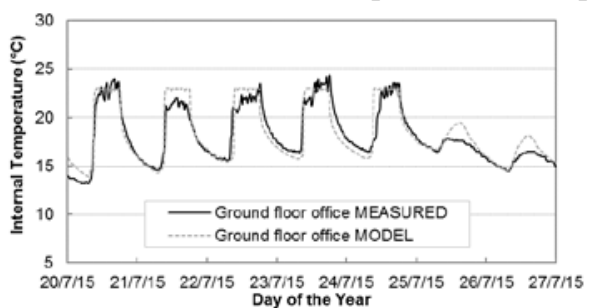

Fig. 4. TTT ground floor validation (winter).

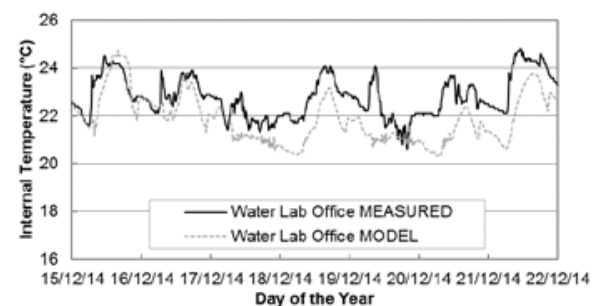

Fig. 5. SBRC water lab validation (summer).

A very poor correlation was observed for the Energy Laboratory zone at SBRC. The measured data for this room during winter and summer periods appeared very erratic when compared to data from other rooms. One possible cause of this may have been due to the temperature sensor being located next to an entrance door. An air exchange with the adjacent space, and air flow across the sensor caused by motion of the door, may cause fluctuations and contribute to poor correlation. Another poor correlation was observed for the Eastern Office. Modelling of large, naturally ventilated spaces using this modelling technique is often unpredictable given various local weather effects not considered by the weather file. Temperature profiles will not always be a perfect match and thus the $\mathrm{R}^{2}$ value may not be the best indicator of success. Modelling the large open plan office area as several discrete zones may have improved this result. From a validation perspective, modelled temperature within naturally ventilated spaces still follow approximately actual building control (Fig. 6).

\subsection{Energy Validation}

Validation of the energy details of each building model was undertaken. Validation for TTT lighting system is shown in Fig. 7 for three months of data. Each peak and trough represents a full week (weekend consumption significantly lower than weekdays). NMBE was $12 \%$ indicating the model under predicts energy use. CVRMSE was 38\%. Lighting and equipment use was heavily influenced by human behavior, which is difficult to predict for 
unconventional buildings. A larger sample size or higher resolution data may improve correlation. Inspection of Fig. 7 indicates the model is generally representative of the lighting system when unforeseen increases or decreases are discounted. HVAC model comparison for TTT is shown in Fig. 8. The model was not as successful at predicting energy use, with NMBE of $12 \%$ and CVRMSE of $50 \%$. Nonetheless, the model follows measured patterns, and peak energy use in most cases compares well. 'Simple' HVAC setting in DesignBuilder was used, which assumes a nominal coefficient of performance (COP) and constant loads for pumps. With additional time, a more representative HVAC model could be developed.

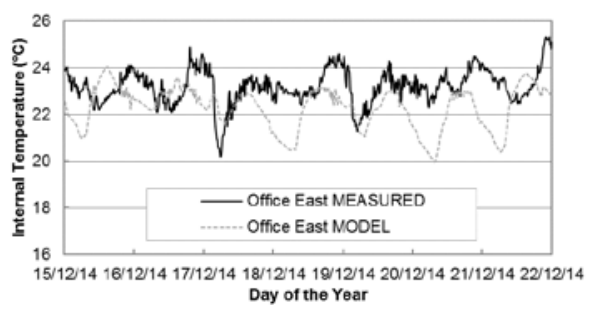

Fig. 6. SBRC office thermal validation (summer).

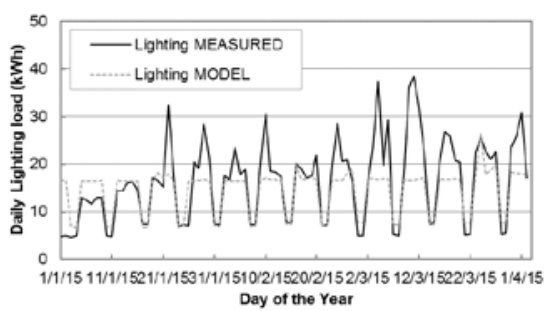

Fig. 7. TTT lighting electrical use validation.

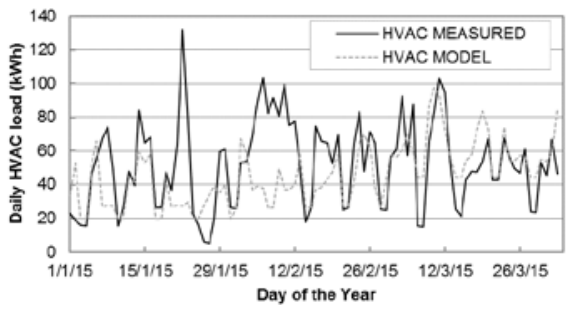

Fig. 8. TTT HVAC electrical validation.

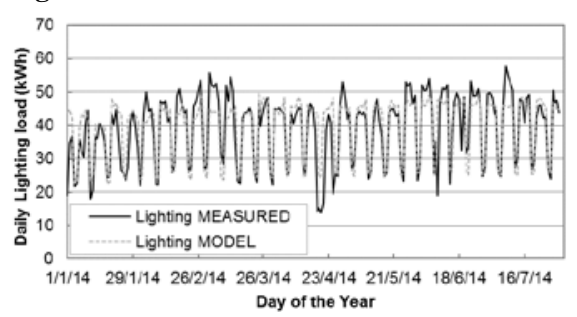

Fig. 9. SBRC lighting electrical use validation.

Validation of energy aspects of SBRC model was hampered by data availability. Eight months of data was available for lighting, and a full year for HVAC. However, general loads and building services were metered separately and technical difficulties prevented recording. Additionally, SBRC was in its first year of occupation and commissioning of some systems occurred during early months, notably HVAC. Nonetheless, enough data was available to provide a degree of confidence. Energy profile comparison of modelled lighting system with real consumption is shown in Fig. 9. NMBE of $-1.3 \%$ and CVRMSE of $16.4 \%$ for lighting suggests the model doesn't quite fit the data. SBRC lighting systems are influenced by occupants and external weather conditions, with occupancy and daylight sensors controlling operation. On several occasions lighting energy was underestimated for the week. This was due to higher than normal occupancy, and lower natural light levels from a run of inclement weather days. HVAC profile comparison is shown in Fig. 10. NMBE was $2.7 \%$, and CVRMSE was $45.8 \%$. As per TTT, the SBRC model did not consider detailed HVAC specifications, only nominal COP and auxiliary. Generally HVAC compares well on a larger timescale, with the model showing winter period providing highest demand. Three peaks during the first three months indicate when commissioning was in progress.

Metering at Enterprise 1 was less extensive. However, as Enterprise 1 had been operating for longer, a full year of more reliable data was available. Unfortunately, the energy model is only able to be validated for HVAC and combined light and power loads, as lighting and general loads were metered together. Energy use comparison for light and power is shown in Fig. 11. NMBE was 1.7\% and CVRMSE was 5.9\%. The model tends to reduce consumption from August, while in reality the opposite trend occurs. Apart from this discrepancy, light and power comparison was validated. HVAC energy use comparison is shown in Fig. 
12. A good visual comparison is observed. NMBE of $2.8 \%$ and CVRMSE of $21.7 \%$ confirmed the HVAC model is the best representation of all buildings. Enterprise 1 HVAC was more conventional compared to experimental systems at SBRC and TTT. Occupancy of Enterprise 1 is higher and steadier, making electrical load profiles more predictable.

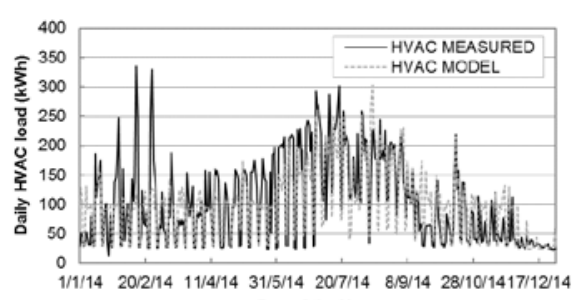

Day of the Year

Fig. 10. SBRC HVAC electrical comparison.

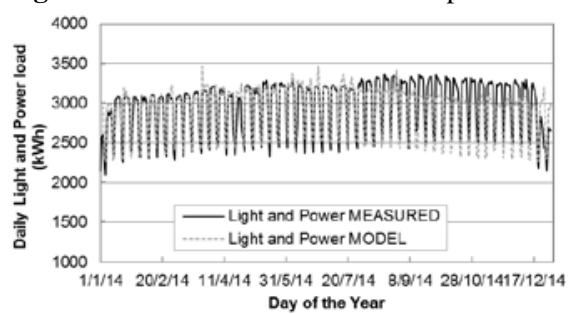

Fig. 11. Enterprise 1 electrical use comparison.
Table 4. Energy Model Validation Results.

\begin{tabular}{llll}
\hline & $\begin{array}{l}\text { Building } \\
\text { system }\end{array}$ & $\begin{array}{l}\text { NMBE } \\
\text { Avg. (\%) }\end{array}$ & $\begin{array}{l}\text { CVRMSE } \\
\text { Avg. (\%) }\end{array}$ \\
\hline TTT & Lighting & 12.5 & 38.4 \\
& General & 5.9 & 18.1 \\
& HVAC & 12.2 & 50.1 \\
\hline \multirow{2}{*}{ SBRC } & Lighting & -1.3 & 16.4 \\
& HVAC & 2.7 & 45.8 \\
\hline E1 & Light \& power & 1.7 & 5.9 \\
& HVAC & 2.8 & 21.7 \\
\hline
\end{tabular}

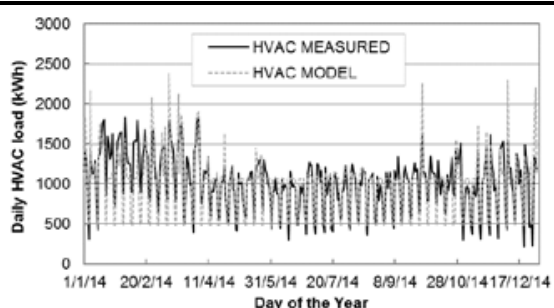

Fig. 12. Enterprise 1 HVAC comparison.

Models can only be as good as the data and assumptions used to verify it. For the three building models presented, none had complete energy data able to represent each season of the year. This is expected, for most buildings will rarely have anything other than utility billing and energy readings available. TTT was only able to be verified against energy data for summer and autumn. SBRC and Enterprise 1 had a full year of HVAC data, but other aspects of energy use were missing or not individually metered in the first instance. Where data is incomplete, reasonable assumptions based on typical values or technical information must be relied on. Light and power were lumped into one meter at Enterprise 1 making it difficult to validate the lighting model, however, reviewing documentation on lighting in the real building enabled correct sizing. Whilst simulation results cannot be directly compared to metered data, the assumptions are able to be relied upon.

Model validation of complex high efficiency buildings is more challenging than conventional buildings due to intelligent systems which adjust automatically depending on a range of environmental variables, such as natural light. This makes energy consumption more variable and thus difficult to model where provision of specific environmental inputs are not made. Summarized results of energy validation are shown in Table 4. Enterprise 1 performs the best, however it has less sub-metering and thus only two systems were assessed.

Building size has an effect on model accuracy. One reason why Enterprise 1 achieved better validation is that larger buildings are less sensitive to events such as opening a window. In the smaller SBRC and TTT, events linked to occupant behavior have more influence. Also, occupancy schedules of the largely commercial Enterprise 1 are more predictable than SBRC and TTT where occupancy rates depend on timetabling and special events.

\section{Simulation Results}

By performing DesignBuilder simulations of all three buildings using the validated models, an understanding into the sensitivity of each building to changes in design from the point of view of energy consumption can be gained. From this, better informed decisions 
can be made when designing a NZEB or considering energy efficiency upgrades to existing buildings. From Fig. 13 it is observed that the NZEBs are similar in their energy use breakdown, with lighting being the smallest component, and HVAC roughly $50 \%$ of overall load. By contrast, HVAC loads at Enterprise 1 are the smallest component, making up only one quarter of overall load. This means that different energy outcomes will be expected between the NZEB and conventional building when effects on HVAC energy use are significant.

\subsection{Glazing}

The type of glazing used in a building can affect energy consumption. Different window designs will let different amounts of sunlight into the building. This impacts on how much artificial light is needed to sufficiently illuminate the building. Fig. 14 shows the change in annual energy use for each case study building for different glazing (single LowE, double, double LowE, triple and triple LowE glazing) when compared to a benchmark of singlepane clear glass. The overall effect of higher performance glazing on total energy use across a whole year is a net reduction for the three buildings. The building that benefits most from high performance glazing is SBRC, with TTT experiencing the second highest saving.

\subsection{Lighting Control}

Lighting systems are a significant contributor to overall energy use. For the NZEBs, lighting systems represent $18 \%$ of annual energy consumption. This is contrasted with the more conventional Enterprise 1, where lighting represents 36\% (refer Fig. 13). Lighting specifications for the buildings are provided in Table 5. Enterprise 1 is specified at $320 \mathrm{~lx}$ according to Australian Standard AS 1680 [14]. This value is recommended for "routine office work". The NZEBs have much lower specifications because where there is a deficit in overall lighting, low power localized light sources are utilized to ensure appropriate levels. This enables lower lighting power densities, in conjunction with reliance on daylighting.

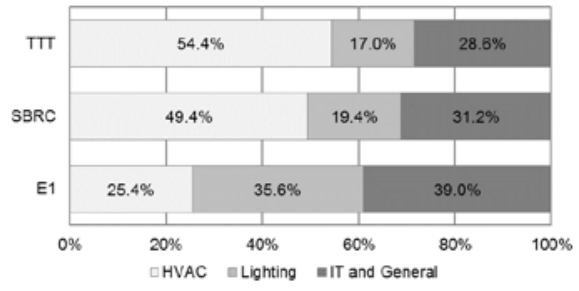

Fig. 13. Energy breakdown of case study models.

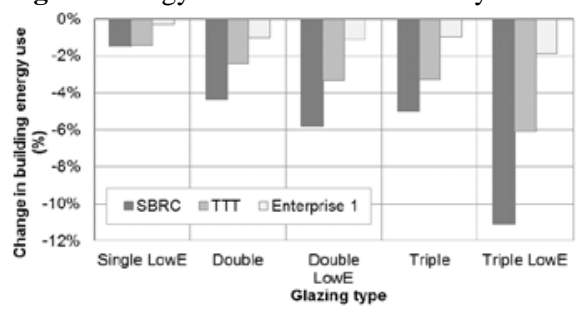

Fig. 14. Glazing vs change in total energy use.
Table 5. Building Lighting Specifications.

\begin{tabular}{llll}
\hline & TTT & SBRC & E1 \\
\hline $\begin{array}{l}\text { Avg. lighting } \\
\text { level (Lux) }\end{array}$ & 193 & 213 & 320 \\
\hline $\begin{array}{l}\text { Avg. power den- } \\
\text { sity (W/m }{ }^{2} \text { ) }\end{array}$ & 4.75 & 1.60 & 9.40 \\
\hline $\begin{array}{l}\text { Avg. density/100 } \\
\text { Lux }\end{array}$ & 2.46 & 0.75 & 2.94 \\
\hline
\end{tabular}

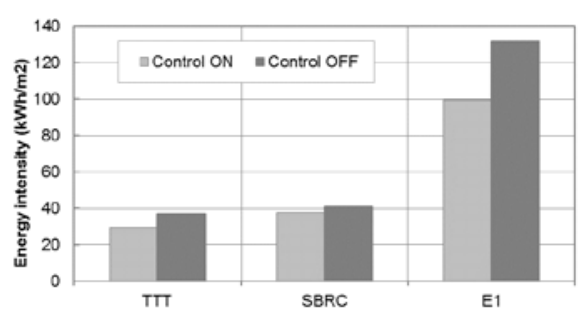

Fig. 15. Lighting vs building energy use intensity

Simulations of controlled lighting output based on available daylight levels were performed. Net effect on overall energy consumption was compared between the three buildings, Fig. 15 illustrating annual energy use intensity for each. Results show Enterprise 1 would have greatest benefit from daylight controls with $25 \%$ reduction in energy use. TTT experiences $21 \%$ energy savings. The smallest impact was at SBRC where only $8 \%$ of energy savings can be attributed to daylight controls. Such a small saving was due to installed 
lighting power density already being low to take advantage of daylighting, and provision of task-based lighting. This is a different at TTT where a higher provision of lighting was installed. Whilst TTT is a NZEB, lighting power density is three times higher than SBRC as a result of the lower aspect ratio and its implications for daylighting.

\subsection{Window shading}

Window shading may be effective in reducing energy consumption. The purpose of shading is to reduce cooling loads and optimize quality of daylight entering the interior. Shading elements are critical to NZEBs, e.g. roof overhang, which must maximize transmission of low winter sun, and minimize high summer sun. Shading techniques include vertical or horizontal louvres. These require knowledge of design and site information, i.e. nearby structures, landmarks, vegetation, and orientation. Simulation of local, building-integrated shading was ignored due to the need for it to be designed specifically according to each building, making it difficult to compare results between models. Horizontal slatted blinds were investigated instead, allowing a common type of shading and control method across all buildings. The blind type used was from the DesignBuilder default library and had reflective slats. Control of window shading was simulated with two different strategies: the first being a seasonal schedule - implemented during summer and winter days and nights; and the second implementing shading when outside temperature exceeded a threshold. Each of the case study buildings had some degree of existing shading such as roof overhangs, window louvres, or both. The window shading implemented did not replace existing shading elements.

The net effect on energy consumption from seasonal shading is shown in Fig. 16. The most effective strategy for the NZEBs was to close all blinds during summer days, with predicted energy saving of 1\%-4\%. For Enterprise 1, overall energy consumption increased by $1 \%$ because lighting makes up a higher proportion of energy consumption. Shading windows during winter nights also results in a net reduction in consumption for SBRC due to a reduction in HVAC (as a result of being able to retain heat). The opposite observation is made for TTT due to an increase in lighting use. Negligible effects on energy consumption were observed for all three buildings when shading is used during summer nights. Increases in energy use when shading is used during winter days was observed. This was due to increases in both lighting and HVAC use of 3\%-8\% for the NZEBs, while Enterprise 1 saw negligible changes in HVAC loads, but a 3.5\% increase in lighting. Lighter columns within Fig. 16 represent the change in lighting energy use in proportion to window to floor area ratio (WFR). This useful metric gives an indication of comparative sensitivity to window shading. From Fig. 16, comparative magnitudes are largely similar to absolute change in energy use. Thus WFR is likely to be a determining factor for change in lighting energy use.

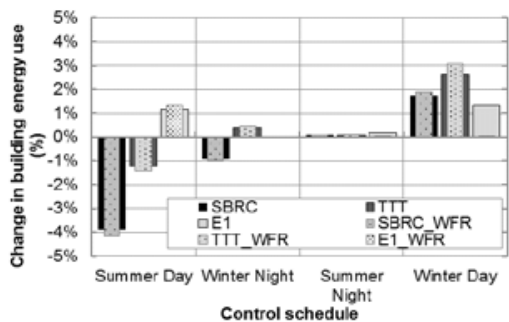

Fig. 16. Shading vs energy use, seasonal control.

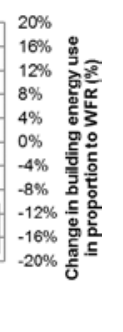

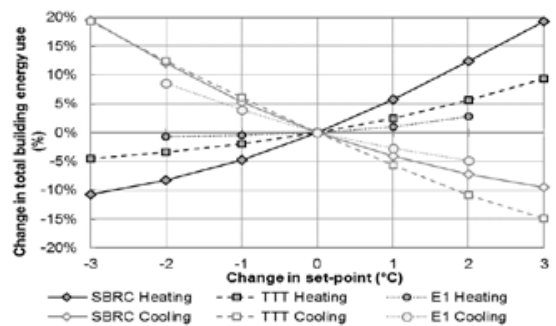

Fig. 17. HVAC set-point vs change in energy.

\subsection{HVAC set-point}

The impact of changing heating and cooling set-point temperatures on energy use was studied. Heating set-points were varied in $1^{\circ} \mathrm{C}$ increments from benchmark temperature while cooling set-point kept constant. Where natural ventilation was employed (for the 
NZEBs), the lower limit of this range followed the heating set-point up and down. Cooling set-point was then varied in $1{ }^{\circ} \mathrm{C}$ increments while heating set-point held constant. The upper limit of the natural ventilation range followed the cooling set-point up and down. A range of $3^{\circ} \mathrm{C}$ was chosen for the NZEBs since comfort bands were wider than Enterprise 1 . The range was $2^{\circ} \mathrm{C}$ for Enterprise 1 due to not being able to increase heating set-point or decrease cooling set-point any further without overlapping. HVAC models were approximated using an idealized calculation method which uses constant COP. This eliminated the need to specify every individual HVAC component - a task which requires information that is often hard to attain and considerable modelling experience to achieve reliable results. Accordingly, the HVAC model is not expected to be a highly accurate representation of real systems. However, relative changes in overall consumption are expected to be broadly reliable.

Fig. 17 illustrates how changes in HVAC set-point translate into overall energy consumption for the three buildings. SBRC is most responsive to changes in heating set-point. For the cooling set-point case, SBRC and TTT models are equally sensitive to set-point reductions. TTT is most sensitive to increases in cooling set-point. In all cases, Enterprise 1 was least sensitive to set-point changes with negligible savings achieved and a $2.5 \%$ energy increase observed for the heating case. In the cooling case, Enterprise 1 achieved up to 5\% energy saving for a $2^{\circ} \mathrm{C}$ increase in set-point. Where the cooling set-point was decreased, energy consumption of Enterprise 1 increased up to 8.5\%.

Applications of HVAC set-points must consider occupant comfort. Increasing cooling set-point from $24^{\circ} \mathrm{C}$ to $26^{\circ} \mathrm{C}$ at Enterprise 1 would result in $25 \%$ energy savings, and $5 \%$ $15 \%$ may be achievable for the (already efficient) NZEBs. However this would not be feasible if occupants were not comfortable. Saving 10\% in energy at SBRC is unlikely worthwhile given heating set-point must be lowered by $3^{\circ} \mathrm{C}$ to $16.5^{\circ} \mathrm{C}$. Similarly TTT may save $15 \%$ if cooling set-point was raised by $3^{\circ} \mathrm{C}$ to $27.5^{\circ} \mathrm{C}$, but these are beyond acceptable limits.

\section{Discussion}

Benefits of high performing glazing technology are noticeable at the NZEBs and to a smaller degree at Enterprise 1. Where lighting and power loads are dominant, higher performance glazing upgrades have less effect, e.g. triple glazing offered a $1.9 \%$ reduction in energy use compared to single glazed at lighting dominated Enterprise 1. Whilst an 11\% reduction in HVAC was predicted, lighting load was a greater portion of overall energy.

A simulated retrofit of daylighting controls to Enterprise 1 found that a $25 \%$ reduction in energy use could be achieved. Simulations of TTT and SBRC show that daylighting controls contribute to savings of $21 \%$ and $8 \%$. The low figure associated with SBRC was due to an existing reliance on daylighting and low installed lighting power density.

Where shading was controlled according to a temperature threshold $\left(26^{\circ} \mathrm{C}\right)$, NZEBs experienced savings of 1-2\%, while Enterprise 1 experienced a small increase. Effects are diminished with increasing temperature due to a mild climate (temperatures only above $26^{\circ} \mathrm{C} 8 \%$ of time). Overall, window shading on all three case study buildings resulted in marginal energy savings for the type and control investigated. Enterprise 1 experienced a net increase in consumption for shading due to lighting being the larger and more sensitive load. With lower lighting loads, NZEBs achieved small savings for seasonal control.

Simulations showed that Enterprise 1 was least sensitive to changes in HVAC set-point, despite having the narrowest comfort band. Energy consumption at SBRC and TTT was seen to increase significantly when cooling set-point was lowered or heating set-point raised. The decrease in energy consumption was equally as significant despite the wider comfort band employed in the NZEBs. The reason for this is likely building energy use 
breakdown (refer to Fig. 13). The HVAC component makes up 54\%, 49\% and 25\% of overall building energy consumption at TTT, SBRC and Enterprise 1 respectively.

The NZEBs were designed to operate at a higher performance level and are more finely tuned. For example, lighting power density is reduced in NZEBs due to their reliance on daylighting. HVAC set-points are generally set wider in NZEBs in a bid to save energy. This must be balanced with occupant comfort standards. Future work proposed aims to more comprehensively validate each model using a complete year of weather and energy data. Occupant behavior has also been greatly simplified and requires further investigation.

\section{Conclusion}

Model validation of efficient buildings is more challenging than conventional buildings due to intelligent systems which adjust automatically depending on a range of environmental variables. This makes energy consumption more variable than conventional buildings and thus difficult to model where provision of specific environmental inputs is not made.

Higher performance glazing offers benefits for NZEBs with dominant HVAC loads. Daylighting controls may provide significant energy benefits where high fenestration levels exist with daytime occupancy. Window shading is a complex design area and could not be fully investigated without significant changes to the envelope of each building. Instead, local shading of windows using reflective slatted blinds was simulated. Results showed that the net benefit for all buildings was low due to an increased requirement for artificial lighting offsetting any benefits made to HVAC. Other forms of shading would likely provide different results and further modelling is worthwhile. Where HVAC is the dominant load, set-point adjustment, installing higher performance glazing, and window shading can help produce significant reductions in energy use. Where HVAC is less significant, these changes will have less impact, and a more worthwhile change may be to install daylight controls.

\section{References}

1. H. Sozer, "Improving energy efficiency through the design of the building envelope," Building and Environment, vol. 45, no. 12, pp. 2581-2593, 2010.

2. R. Pacheco, J. Ordóñez, G. Martínez, "Energy efficient design of building: A review," Renewable and Sustainable Energy Reviews, vol. 16, no. 6, pp. 3559-3573, 2012.

3. A. J. Marszal, P. Heiselberg, J. S. Bourrelle, et al., "Zero energy building - A review of definitions and calculation methodologies," Energy and Buildings, vol. 43, no. 4, pp. 971-979, 2011.

4. S. Pless, P. Torcellini, "Net-zero energy buildings: A classification system based on renewable energy supply options," NREL Report, NREL/TP-5500-44586, pp. 1-14, 2010.

5. S. B. Sadineni, S. Madala, R. F. Boehm, "Passive building energy savings: A review of building envelope components," Renew. and Sust. Energy Reviews, vol. 15, no. 8, pp. 3617-3631, 2011.

6. S. M. Bambrook, A. B. Sproul, D. Jacob, "Design optimisation for a low energy home in Sydney," Energy and Buildings, vol. 43, no. 7, pp. 1702-1711, 2011

7. L. Pérez-Lombard, J. Ortiz, C. Pout, "A review on buildings energy consumption information," Energy and Buildings, vol. 40, no. 3, pp. 394-398, 2008.

8. M. Bodart, A. D. Herde, "Global energy savings in offices buildings by the use of daylighting," Energy and Buildings, vol. 34, no. 5, pp. 421-429, 2002.

9. M. Krarti, P. M. Erickson, T. C. Hillman, "A simplified method to estimate energy savings of artificial lighting use from daylighting," Building and Environment, vol. 40, no. 6, pp. 747-754, 2005.

10. M. Dubois, Å. Blomsterberg, "Energy saving potential and strategies for electric lighting in future North European, low energy office buildings," Energy and Buildings, vol. 43, no. 10, pp. 2572-2582, 2011.

11. NSW Office of Environment and Heritage, "National Australian Built Environment Rating System (NABERS)," https://www.nabers.gov.au/, [Accessed Mar 2016].

12. DesignBuilder Software Ltd, "Simulation Documentation," DesignBuilder, p. 822, 2015.

13. ASHRAE Guideline 14-2002, "Measurement of Energy and Demand Savings," American Society of Heating, Refrigerating and Air-Conditioning Engineers, p. 170, 2002.

14. AS/NZS 1680.1:2006, "Interior and workplace lighting, Part 1: General principles and recommendations," Australian/New Zealand Standards, 2016. 